\title{
Survival rate of multi-drug resistant tuberculosis among human immunodeficiency virus co-infected patients in Sanglah Hospital/Udayana University, Bali, Indonesia: a cohort retrospective study
}

\author{
Ivana Beatrice Paulus ${ }^{1}$, Feliani Sanjaya ${ }^{1}$, Ni Made Dewi Dian Sukmawati ${ }^{2}$ \\ ${ }^{1}$ Medical Faculty of Udayana University, Bali, Indonesia \\ ${ }^{2}$ Department of Infectious Diseases and Tropical Medicine, Sanglah Public General Hospital/Medical Faculty of Udayana University, \\ Bali, Indonesia
}

\begin{abstract}
Introduction: Tuberculosis (TB) and human immunodeficiency virus (HIV) are corelated infectious diseases and their worldwide spread became a global health problem. Moreover, HIV patients with TB are able to develop multi-drug resistance tuberculosis (MDR-TB) and extensive drug-resistant TB (XDR-TB), which make treatments more challenging and affect survival rate. This study aimed to observe survival rate of HIV-positive patients with MDR-TB.

Material and methods: This retrospective, analytical study was conducted in Sanglah Public Hospital from February till April 2018. Data was obtained using total sampling; 98 samples were collected from medical records, including $19 \mathrm{HIV}$-infected and 77 non-HIV patients, who fulfilled inclusion and exclusion criteria. Analysis was performed with univariate and bivariate survival analysis. Primary outcome was survival.

Results: Median age was 40 (range, 12-65) years; in HIV group, it was 38 (range, 23-65) years and 40 (range, 12-63) years in non-HIV group. Gender ratio between male and female was nearly $1: 1$; association between HIV status with outcome was significant, but statistical $(p<0.0001)$ and cofounding variables were not. Mean of survival in HIV group was significantly shorter than in non-HIV group ( $2.6 \pm 0.5$ years vs. $5.1 \pm 0.2$ years), and 5 -year survival rate was $52.1 \%$ vs. $81.9 \%$, respectively. Mantel Cox was applied to compare log-rank test, with significant association between HIV status and survival $(p=0.001)$. Survival rate hazard ratio for MDR-TB in HIV group was 4.17 (range, 1.67-10.4).
\end{abstract}

Conclusions: Decreasing outcome and survival rate among are considered factors associated with MDR-TB in HIV-positive patients than in non-HIV-infected individuals.

HIV AIDS Rev 2021; 20, 2: 109-113 DOI: https://doi.org/10.5114/hivar.2021.107237

Key words: HIV, multi-drug resistance, survival, tuberculosis.

Address for correspondence: Ivana Beatrice Paulus, Medical Faculty of Udayana University, Bali, Indonesia, P.B. Sudirman street, Denpasar - Bali 80232, e-mail: ivanabeatrice@student.unud.ac.id
Article history:

Received: 06.09.2020

Received in revised form: 27.09.2020

Accepted: 05.10.2020

Available online: 30.06 .2021
International Journal of HIV-Related Problems

HIV \& AIDS

R e vi e w 


\section{Introduction}

Tuberculosis (TB) and human immunodeficiency virus (HIV) are infectious diseases that became a global health problem, with high mortality and morbidity. According to the World Health Organization (WHO) report, there were 10.4 million people suffering from $\mathrm{TB}$, with a mortality rate of 1.8 million deaths in 2015. Moreover, one out of three HIV-positive people was found to have TB in 2015 [1].

Number of cases and deaths resulting from TB has reduced worldwide, and the increase of global TB incidence has been stopped and began to show a decline of around $2 \%$ per year in 2012 , with mortality reduced by $45 \%$ compared to 1990. In Indonesia, the mortality and morbidity rates due to TB have decreased by $50 \%$ in 2015 compared to 1990 [2]. However, the number of new BTA-positive cases and all TB cases in Indonesia is increasing each year. This is related to the epidemic of HIV/AIDS, which started to emerge in the 1980s, reporting the existence of TB resistance to anti-tuberculosis drugs (ATD) in the late 1980s and early 1990s. [3].

Pulmonary TB is caused by Mycobacterium tuberculosis and tends to infect patients with compromised immune system; therefore, HIV-positive patients are very vulnerable to TB infection. In addition, pulmonary TB disease is the main cause of death in HIV-positive patients, and one out of three deaths in patients with HIV is caused by TB; in 2015, nearly $35 \%$ of HIV-infected patients have died from TB [4].

Over the past few years, the number of reported multidrug resistance tuberculosis (MDR-TB) cases is constantly growing. MDR-TB is a TB bacterium resistant to isoniazid (INH) and rifampicin, with or without other first-line ATD [3]. Worldwide, in 2015, around 480,000 people suffered from MDR-TB, and 9.5\% of MDR-TB patients additionally experienced extensive drug-resistant TB (XDR-TB). This condition certainly complicate TB treatment. It is known that only $52 \%$ of MDR-TB patients and $28 \%$ of XDR-TB cases in the world have managed to recover [5].

Conditions of HIV-positive TB patients are able to affect the development of TB bacteria, which may lead to MDRTB [6]. Gastrointestinal disorders in HIV patients can cause malabsorption of OAT, which reduces OAT's bio-availability, low levels of adherence to therapy, treatment of other opportunistic infections, consumption of antiretroviral drugs, and the use of intermittent TB treatment regimens that potentially lead to MDR-TB development $[7,8]$.

Immune-compromised condition, such as HIV-infection, lead to worse outcomes in MDR-TB patients. a study in Peru found that more than $50 \%$ of HIV-infected MDR-TB patients have died within two months of diagnosis [9]. This result was supported by a UK study, which estimated that immune-compromised MDR-TB patients were nine times more likely to die than those who were not immune-compromised [10].

Based on the previously described importance of tuberculosis in HIV-positive patients, especially MDR-TB, the present study was conducted to review the survival rate of HIV-positive patients with MDR-TB.

\section{Material and methods}

This study was analytical study, with cohort retrospective design, and it was conducted in Sanglah General Hospital from February till April 2018. Samples were taken from medical records in installation room of programmatic management of drug resistant tuberculosis (PMDT) Sanglah General Hospital, Denpasar. Sanglah General Hospital is the central and referral hospital in Bali as well as teaching hospital. the PMDT clinic was established in 2007, and it has been chosen to be a study area, with complete data storage.

Total sampling method was used according to inclusion and exclusion criteria. Criteria of inclusion was a HIV-infection and diagnosis of TB multi-drug resistance with a clinical manifestation, and laboratory findings in Sanglah Hospital, while exclusion criteria were conditions, such as infection, cancer, tumor, or altered chronic and life-threatening diseases. Moreover, participants were excluded if they had previous MDR tuberculosis treatment, resistance to fluoroquinolones, or second-line injectable agents as well as pregnancy. In total, 96 patients who fulfilled the above criteria were included, with 19 cases in HIV group and 77 patients in non-HIV-infected group, who were diagnosed with MDR since 2012. Secondary data was obtained from medical records of the patients. the primary outcome of interest was time from TB diagnosis to death, which was calculated by subtracting the date of death from the date of TB diagnosis. the patients were censored at the date of the last visit if they were lost to follow-up or on the date of referral.

MDR-TB was defined as a case with pulmonary tuberculosis not responded to at least isoniazid and rifampicin, and was diagnosed using genotypic (or molecular) methods, GeneXpert System (Xpert MTB/RIF, Cepheid, USA). HIV diagnosis details were extracted from medical records, and physical examination, risk of transmission, opportunistic infection, and laboratory examination with antibody test ELISA were additionally acquired.

The permission for conducting the study has been obtained and approved with a letter of ethical negligence from a research ethics commission of Udayana University Faculty of Medicine/Sanglah General Hospital, Denpasar as well as a consent attained from Education and Research Division of Sanglah General Hospital, Denpasar. All the participants' information collected during the research were kept confidential.

This study was using univariate and bivariate analysis, and variables included age, sex, survival, and HIV status. Numeric data, such as age, was tested with Kolmogorov-Smirnov normality test, and categorical data by cut-off that were obtained from consensus and latest research. Numeric data were presented with means and standard deviation (SD) for normally distributed data, while abnormally distributed data were shown with median and interquartile range (IQR). Normality and frequency test was used as univariate analy- 
Table 1. Participants' characteristics at enrollment

\begin{tabular}{l|c|c|c}
\hline Characteristic & Total $(n=96)$ & HIV-positive $(n=19)$ & HIV-negative $(n=77)$ \\
\hline \begin{tabular}{l} 
Age \\
\hline$<60$ years
\end{tabular} & $89(92.7)$ & $19(21.3)$ & $70(78.6)$ \\
\hline$\geq 60$ years & $7(0.07)$ & $1(14.3)$ & $6(85.7)$ \\
\hline Female & $39(40.6)$ & $7(8.5)$ & $32(91.4)$ \\
\hline \begin{tabular}{l} 
Outcome \\
\hline Survive
\end{tabular} & $76(79.2)$ & $10(13.1)$ & $66(86.8)$ \\
\hline Death & $20(20.8)$ & $9(45)$ & $11(55)$ \\
\hline \begin{tabular}{l} 
Resistance \\
\hline Isoniazid
\end{tabular} & $26(27.1)$ & $4(15.3)$ & $18(84.6)$ \\
\hline Rifampin & $82(85.4)$ & $17(20.7)$ & $65(79.2)$ \\
\hline Pyrazinamide & $1(1.0)$ & $0(0.0)$ & $1(1.0)$ \\
\hline Ethambutol & $12(12.5)$ & $1(9.0)$ & $11(90.9)$ \\
\hline Streptomycin & $9(9.4)$ & $0(0.0)$ & $9(9.0)$ \\
\hline
\end{tabular}

Values are presented as $n$ (\%), unless otherwise indicated. HIV - human immunodeficiency virus

sis to describe characteristics, proportion of sample, and to determine the type of test used in bivariate analysis. $c^{2}$ test was applied to describe the association between HIV and outcomes. Survival was interpreted as time in years and analyzed with Kaplan-Meier. Association was explained using log-rank analysis. Confounding variable was also analyzed in this study, but the results were not significant $(p>0.25)$, therefore not used in multivariate analysis. That variable was not confounding factor in this study. Since the survival analysis was assessed by Kaplan Meier and it fulfilled the proportion of hazard, it was continued with hazard analysis and regression. Statistical analysis was performed using Statistical Package for Social Sciences v. 23 software (IBM Corp., Armonk, NY, USA).

\section{Results}

Characteristics of the present study are described in Table 1. the overall median age was 40 (range, 12-65) years, particularly, in HIV group, it was 38 (range, 23-65) years and in non-HIV group, it was 40 (range, 12-63) years. the female-male gender ratio was nearly $1: 1$. Out of $20.8 \%$ of deaths, nearly half ( $45 \%$ of deaths) included patients with HIV. Other variables, such as age and sex, were analyzed using $\chi^{2}$ test, and the results were above 0.05 (0.63 and 1, respectively). There was a significant association between HIV status and outcomes, and the other variables were not statistically significant.

In this study, the average follow-up was 72 months. the overall median survival rate of the included 96 patients was $4.7 \pm 0.2$ years. Nineteen $(20 \%)$ patients died. Based on Kaplan-Meier analysis, the 5-year survival rate of HIV-positive patients was estimated at $52.1 \%$ vs. nonHIV $81.9 \%$, while 1-year and 3-year survival rates were $52.1 \%$ in the HIV group vs. $85.6 \%$ in the non-HIV cohort,

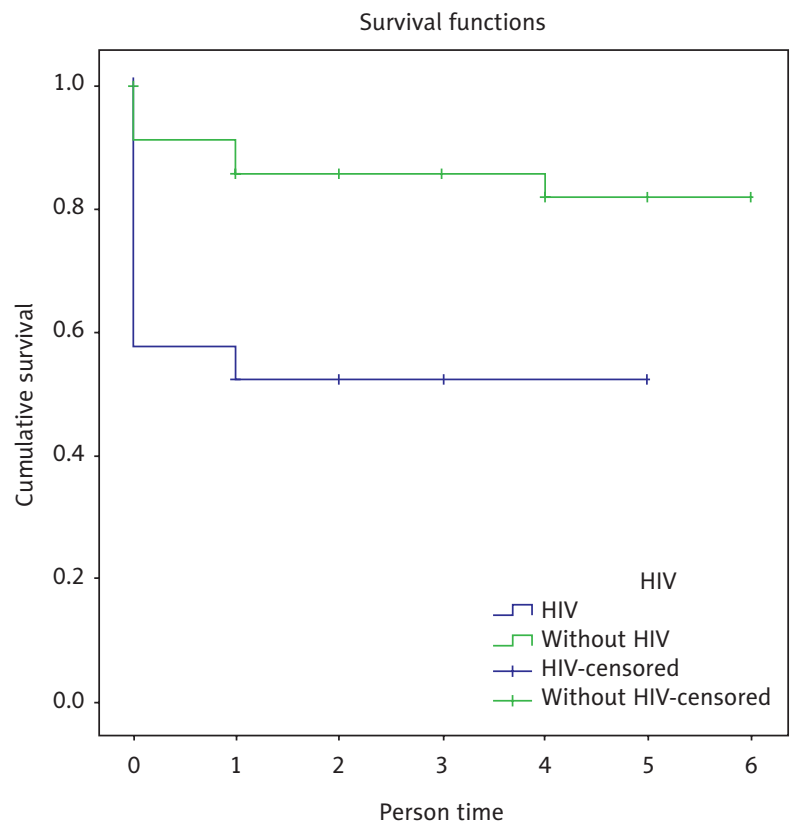

Figure 1. Survival plots

respectively. the mean time of survival between HIV and non-HIV patients was evaluated using Kaplan-Meier test, and in the HIV group, it was significantly shorter than in the control group $(2.6 \pm 0.5$ vs. $5.1 \pm 0.2$ years $)$. Mantel Cox was used to compare log-ranks' results, which indicated a significant association between HIV status and survival $(p=0.001)$ (Figure 1$)$.

HIV was statistically significant in Cox regression analysis, while age and sex were not statistically significant. the hazard ratio for MDR-TB with HIV was 4.17 (range, 1.67-10.4) (Table 2). 
Table 2. HIV variable and survival rate of MDR-TB co-infected patients (Cox's proportional hazard model)

\begin{tabular}{l|c|c|c}
\hline Variable & HR & $95 \% \mathrm{Cl}$ & $p$-value \\
\hline Sex & 1.096 & $0.42-2.80$ & 0.849 \\
\hline HIV & 4.177 & $1.67-10.40$ & 0.002 \\
\hline Age & 1.904 & $0.41-8.640$ & 0.404 \\
\hline
\end{tabular}

\section{Discussion}

In general, this study investigated the association between patients' HIV status and survival rate by evaluating various characteristics, including age, sex, HIV status, and outcome. As previously mentioned, out of the 96 participants included, 19 were HIV-infected patients and 76 were HIV-negative patients. Patients with an infection, cancer, tumor, or with chronic altered and life-threatening diseases were excluded. a biological mechanism, which explained a correlation between development of resistance in TB and HIV infection was suggested. Drug malabsorption in HIV-infected patients can affect development of M. tuberculosis drug resistance. This pathobiology mechanism may lead to treatment failure and progression of TB in immune-compromised individuals, especially with HIV-infection. However, this hypothesis has not yet been confirmed in humans [11].

In previous studies, mortality rates were higher in HIV-infected MDR-TB patients, with pooled mean mortality of $38 \%$ (95\% CI: $28-48 \%$ ) [12-16]. These results were supported by retrospective studies on HIV co-infected patients that suggested survival related to a degree of immunosuppression and HAART use $[15,17,18]$. Additionally, MDR-TB treatments' regimens were associated with many side effects that might possibly lead to synergistic side effects with HAART and adherence to both regimens, therefore, resulting in poor MDR-TB outcomes and HIV virologic failure $[16,19]$.

Latest study conducted by Brust et al. in South Africa is in line with the present study showing HIV infection significantly associated with survival rate. This observational study conducted in South Africa between 2011 and 2013, analyzed survival and cure rates among $150 \mathrm{HIV}$-positive patients and 56 non-HIV-infected individuals, both groups with confirmed MDR-TB. There was a greater proportion in HIV group, in which twenty-four (12\%) patients died during MDR-TB treatment, with a median survival time of 281 days (IQR, 99-618) in those who died; in this group, HIV status did not differ significantly $(p=0.12)$. the present study revealed that $\mathrm{CD} 4+$ count determined the survival rate among HIV-infected patients with MDR-TB. Patients with baseline CD4+ count of $\leq 100$ cells $/ \mathrm{mm}^{3}$ had substantially lower survival than HIV-uninfected MDR-TB patients $(67 \%$ vs. $94 \%$ at 3 -year follow-up; $p=0.005$ ) and the lowest survival of $29 \%$ was among patients whose CD4+ count did not improve to more than 100 cells $/ \mathrm{mm}^{3}$. Moreover, sex and age did not contribute in the survival rate [16]. a meta-analysis conducted by Poorolajal et al. among 294,662 participants, classified survival probabilities of progression from HIV diagnosis to AIDS onset into 2-, 4-, 6-, 8-, 10-, and 12-year survival probabilities. This meta-analysis showed an estimation of probability of $82 \%$ [20]. Furthermore, 2-, 4-, 6-, 8-, $10-$, and 12-year survival probabilities of progression from AIDS onset of AIDS-related deaths in patients who received HAART were estimated to be $87 \%, 86 \%, 78 \%$, and $61 \%$, respectively. In addition, 2-, 4-, and 6-year survival probabilities of progression from AIDS onset to AIDS-related deaths in patients who did not receive HAART, were estimated to be $48 \%, 26 \%$, and $18 \%$, respectively [20]. a retrospective cohort study was conducted among HIV-positive patients with TB, who received HAART and did not receive HAART. a total of 1,003 patients were enrolled in this study, and survival rates at 1-, 2-, and 3-year after TB diagnosis were 96.1\%, $94.0 \%$, and $87.7 \%$, respectively for HAART+ group, and $44.4 \%, 19.2 \%$, and $9.3 \%$ for HAART- group. This retrospective cohorts' results are consistent with the current study, in which HIV patients with TB had a lower survival rate [21]. Nadir CD4+ $<50 \mathrm{~mm} / \mathrm{l}$ has been reported to be associated with survival of six-month mortality of critically ill HIV patients in Mande research [22]. Shin et al. indicated the same results that HIV-infected MDR-TB patients with CD4+ T cell counts $<100$ cells $/ \mathrm{mm}^{3}$ were at higher risk of death compared to non-HIV-infected patients $(\mathrm{RR}=1.890 ; 95 \% \mathrm{CI}$ : 1.098-3.254\%) after investigating sex, age, and prior history of TB treatment [23]. Meta and systematic review conducted by Isaakidi revealed $56.9 \%$ of treatment success and $38 \%$ of mortality among HIV-infected adults with MDR-TB [24]. a retrospective cohort study was performed among HIV-patients with $\mathrm{TB}$, who received HAART and did not receive HAART. a total of 1,003 patients were included into this study, and 1-, 2-, and 3-year survival rates after TB diagnosis were $96.1 \%, 94.0 \%$, and $87.7 \%$, respectively for HAART+ group, and $44.4 \%, 19.2 \%$, and $9.3 \%$ for HAART- group. This retrospective cohort study's results are consistent with a study, in which HIV-infected patients with TB had a lower survival rate [21]

\section{Limitation}

In our study, there are several limitations. CD4+ count level was not evaluated either at the baseline or at the end of study. Moreover, HIV-related treatment variables, including ART failure and interruption could influence the outcomes of the patients.

The limitations of the present study also include its retrospective nature and that the patients' clinical condition might be underestimated. Various important factors, such as chest radiograph pattern, level of immunosuppression (CD4+ count), and type of MDR-TB infection (primary or secondary) were not assessed. Other limitation was low number of sample, with only 96 individuals who fulfilled inclusion and exclusion criteria. In order to validate our initial results, more studies are needed, with larger cohorts of patients. 


\section{Conclusions}

This study demonstrates shorter survival rates among HIV-positive MDR-TB patients than in non-HIV-infected MDR-TB individuals.

\section{Acknowledgements}

We are thankful to the study team of the Voluntary Counselling and Testing (VCT) and Multi-Drug Resistance Tuberculosis (MDR-TB) Clinic of Sanglah General Hospital, Teaching Hospital of Udayana University, for their tireless efforts in data collection and recording. Also, we would like to thank Dr. Ni Made Dewi Dian Sukmawati as well as the doctors and staff of Sanglah General Hospital for their outstanding clinical management of the study participants.

\section{Conflict of interest}

The authors have no conflict of interest.

\section{References}

1. WHO. WHO | Tuberculosis and HIV. WHO [Internet]. 2015 Available from: http://www.who.int/hiv/topics/tb/about_tb/en/ (Accessed: 21.08.2017).

2. Kemenkes RI. Pedoman Nasional Pengendalian Tuberkulosis. Kementrian Kesehatan, Jakarta 2014.

3. Kemenkes RI. InfoDATIN Tuberkulosis. 2016.

4. World Health Organization. Tuberculosis [Internet]. 2017. Available from: http://www.who.int/mediacentre/factsheets/fs104/en/ (Accessed: 17.08.2017).

5. World Health Organization (WHO). WHO | Drug-resistant tuberculosis. WHO [Internet]. 2018. Available from: http://www.who. $\mathrm{int} / \mathrm{tb} /$ areas-of-work/drug-resistant-tb/en/ (Accessed: 28.08.2018).

6. Institute of Medicine. Addressing the Threat of Drug-Resistant Tuberculosis: a Realistic Assessment of the Challenge: Workshop Summary. National Academics Press, Washington 2009.

7. Gurumurthy P, Ramachandran G, Kumar AKH, et al. Decreased Bioavailability of rifampin and other antituberculosis drugs in patients with advanced human immunodeficiency virus disease Antimicrob Agents Chemother 2004; 48: 4473-4475

8. Wells CD, Cegielski JP, Nelson LJ, et al. HIV infection and multidrug-resistant tuberculosis - the perfect storm. J Infect Dis 2007; 196 Suppl 1: S86-107.

9. Coker RJ. Review: multidrug-resistant tuberculosis: public health challenges. Trop Med Int Health 2004; 9: 25-40.

10. Drobniewski F, Eltringham I, Graham C, Magee JG, Smith EG, Watt B. A national study of clinical and laboratory factors affecting the survival of patients with multiple drug resistant tuberculosis in the UK. Thorax 2002; 57: 810-816.

11. Suchindran S, Brouwer ES, Van Rie A. Is HIV infection a risk factor for multi-drug resistant tuberculosis? A systematic review. PLoS One 2009; 4: e5561.

12. Gandhi NR, Shah NS, Andrews JR, et al. HIV coinfection in multidrug- and extensively drug-resistant tuberculosis results in high early mortality. Am J Respir Crit Care Med 2010; 181: 80-86.

13. Brust JCM, Gandhi NR, Carrara H, Osburn G, Padayatchi N. High treatment failure and default rates for patients with multidrug resistant tuberculosis in KwaZulu-Natal, South Africa, 2000-2003. Int J Tuberc Lung Dis 2010; 14: 413-419.
14. Isaakidis P, Casas EC, Das M, Tseretopoulou X, Ntzani EE, Ford N. Treatment outcomes for HIV and MDR-TB co-infected adults and children: systematic review and meta-analysis. Int J Tuberc Lung Dis 2015; 19: 969-978.

15. Gandhi NR, Andrews JR, Brust JCM, et al. Risk factors for mortality among MDR- and XDR-TB patients in a high HIV prevalence setting. Int J Tuberc Lung Dis 2012; 16: 90-97.

16. Brust JCM, Shah NS, Mlisana K, et al. Improved survival and cure rates with concurrent treatment for multidrug-resistant tuberculosis-human immunodeficiency virus coinfection in South Africa. Clin Infect Dis 2018; 66: 1246-1253.

17. O’Donnell MR, Padayatchi N, Kvasnovsky C, Werner L, Master I, Horsburgh CRJ. Treatment outcomes for extensively drug-resistant tuberculosis and HIV co-infection. Emerg Infect Dis 2013; 19: 416424.

18. Dheda K, Shean K, Zumla A, et al. Early treatment outcomes and HIV status of patients with extensively drug-resistant tuberculosis in South Africa: a retrospective cohort study. Lancet 2010; 375: 1798-1807.

19. Bloss E, Kuksa L, Holtz TH, et al. Adverse events related to multidrug-resistant tuberculosis treatment, Latvia, 2000-2004. Int J Tuberc Lung Dis 2010; 14: 275-281.

20. Poorolajal J, Hooshmand E, Mahjub H, Esmailnasab N, Jenabi E. Survival rate of AIDS disease and mortality in HIV-infected patients: a meta-analysis. Public Health 2016; 139: 3-12.

21. Manosuthi W, Chottanapand S, Thongyen S. Survival rate and risk factors of mortality among HIV/tuberculosis-coinfected patients with and without antiretroviral therapy. Clin Sci 2006; 43: 42-46.

22. Manda SO, Masenyetse LJ, Lancaster JL, van der Walt ML. Risk of death among HIV co-infected multidrug resistant tuberculosis patients, compared to mortality in the general population of South Africa. J AIDS Clin Res 2013; Suppl 3: 7.

23. Shin SS, Modongo C, Boyd R, et al. High treatment success rates among HIV-infected multidrug-resistant tuberculosis patients after expansion of antiretroviral therapy in Botswana, 2006-2013. J Acquir Immune Defic Syndr 2017; 74: 65-71.

24. Isaakidis P, Casas EC, Das M, Tseretopoulou X, Ntzani EE, Ford N. Treatment outcomes for HIV and MDR-TB co-infected adults and children: systematic review and meta-analysis. Int J Tuberc Lung Dis 2015; 19: 969-978. 